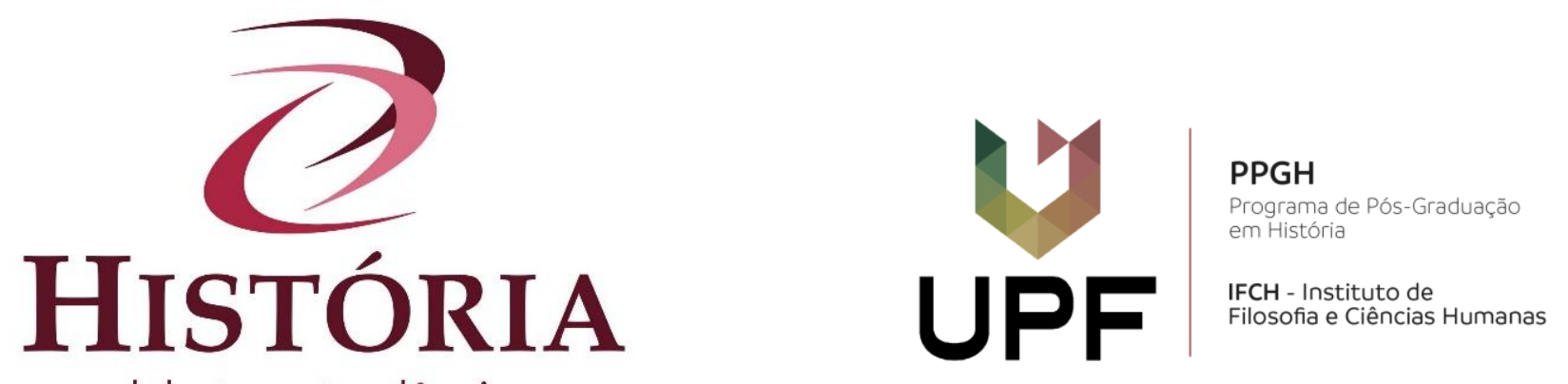

debates e tendências

\title{
Imigração e identidade familiar
}

\author{
Immigration and family identity
}

\author{
Inmigración e identidad familiar
}

Jorge Luiz da Cunha ${ }^{\mathrm{i}}$

\begin{abstract}
Resumo: No extremo sul do território brasileiro, são os imigrantes europeus que inauguram o trabalho familiar em médias e pequenas propriedade, voltadas para o abastecimento do mercado interno. Neste trabalho procura-se analisar e compreender os processos identitários relacionados com a constituição familiar, no caso da colônia de Santa Cruz, fundada pelo governo provincial do Rio Grande do Sul em 1849. As informações coletadas sobre o tema deste projeto revelam claramente um desvelamento (desocultamiento) de atores sociais que em função de seus interesses privados, suas necessidades sociais, as interferências externas (autoridades civis, militares, religiosas), e as articulações da elite tradicional (grandes proprietários) configuram organizações familiares distintas daquelas tradicionalmente associadas aos imigrantes, especialmente os alemães, e a cultura de seus países de origem.
\end{abstract}

Palavras-chave: Imigração alemã. Identidade familiar. Colonização estrangeira.

Abstract: At the southern end of the Brazilian territory, it is the European immigrants who inaugurate family work in small and medium-sized properties, aimed at supplying the domestic market. This paper seeks to analyze and understand the identity processes related to the family constitution, in the case of the Santa Cruz colony, founded by the provincial government of Rio Grande do Sul in 1849. The information collected on the theme of this project clearly reveals an uncovering of social actors who, in the light of their private interests, their social needs, external interferences (civil, military, religious authorities), and the articulations of the traditional elite (great owners) family organizations other than those traditionally associated with immigrants, especially Germans, and the culture of their countries of origin.

Keywords:German Immigration. Family identity. Foreign colonization.

Resumen: En el extremo sur del territorio brasileño, son los inmigrantes europeos que inauguran el trabajo familiar en medianas y pequeñas propiedades, orientadas hacia el abastecimiento del mercado interno. En este trabajo se busca analizar y comprender los procesos identitarios relacionados con la constitución familiar, en el caso de la colonia de Santa Cruz, fundada por el gobierno provincial de Rio Grande do Sul en 1849. Las informaciones recogidas sobre el tema de este proyecto revelan claramente un desvelamiento (desocultivo) de actores sociales que en función de sus intereses privados, sus necesidades sociales, las interferencias externas (autoridades civiles, militares, 
religiosas), y las articulaciones de la élite tradicional (grandes, propietarios) configuran organizaciones familiares distintas de aquellas tradicionalmente asociadas a los inmigrantes, especialmente los alemanes, y la cultura de sus países de origen.

Palabras clave: Inmigración alemana. Identidad familiar. Colonización extranjera.

\section{Introdução}

A família brasileira só bem recentemente despertou a atenção dos historiadores como grupo social de fundamental importância na constituição e evolução da sociedade brasileira. Reduzida aos limites de família patriarcal estudada por Oliveira Vianna, cuja obra lançada em 1918 é considerada um clássico entre os estudos antro-sociológicos brasileiros (2005); e, por Gilberto Freire (2003), com sua influente e igualmente clássica obra Casa Grande \& Senzala, lançada em 1933; e, aí permaneceu até divulgação dos trabalhos de pesquisa de Maria Luiza Marcílio (2000) e Eni de Mesquita Samara (1980, 1986, 1988/89) sobre as famílias paulistas nos séculos 18 e 19 e o trabalho de Iraci del Nero da Costa (1981) sobre a estrutura dos domicílios mineiros. Trabalhos pioneiros, que constituem uma importante contribuição ao desenvolvimento da história da sociedade brasileira

Contudo, é importante salientar que à margem da tipologia familiar construída sobre a matriz lusa, temos, notadamente a partir do século 19, a importação de imigrantes alemães e italianos para as províncias do sul do Brasil, o que implica na constituição de uma nova dinâmica e estrutura familiar, determinadas pelas diferenças culturais e pela característica das atividades econômicas desenvolvidas por esses grupos.

No Rio Grande do Sul, são os imigrantes que inauguram o trabalho familiar na pequena propriedade, voltados para o mercado interno. As colônias de imigrantes alemães se instalam a partir de 1824, com uma interrupção durante a Revolução Farroupilha, entre 1835 e 1845, ii e a retomada do fluxo imigratório somente depois deste período.

Neste trabalho procura-se refletir sobre a família imigrante através de documentos referentes à colônia de Santa Cruz, fundada pelo governo provincial do Rio Grande do Sul, em 1849.

\section{A revolução industrial e a imigração}

A revolução industrial na Europa, significa definitivamente a ruina de grandes massas de artesãos e lavradores que não podem competir no desenvolvimento econômico 
desigual que caracteriza a época, condenando-os, com exército de reserva, a separação de seus meios de produção.

$\mathrm{Na}$ idade média a legislação comunal limitava estritamente o tempo de trabalho dos artesãos. Geralmente se encontra nesta época, além da proibição do trabalho noturno, a paralização do trabalho para numerosas festas religiosas e em épocas fixas do ano:

Partindo do estudo do direito urbano na pequena cidade de Guines, em Artois, Georges Espinas calcula que nessa época o número de dias trabalhados por ano era de 240 (...). Também chega a conclusão de que no século XV, tomando em conta os numerosos dias festivos, a média da semana de trabalho nas minas era de 36 horas semanais. (MANDEL, 1972, p. 122)

Porém, desde que nasce a empresa capitalista começa a desenvolver-se um esforço incessante para prolongar a jornada de trabalho:

A partir do século XVI surge na Grã Bretanha uma legislação dirigida a proibir as jornadas de trabalho demasiado curtas. A literatura britânica dos séculos XVII e XVIII está cheia de queixas referentes a ociosidade dos trabalhadores (...). No século XVIII encontramos na Inglaterra uma jornada de trabalho normal de 13 a 14 horas (...). Como os salários haviam baixado tanto que cada dia de folga era um dia de fome, Napoleão resulta mais generoso que seu ministro Portalis quando rechaça a proposição deste último sobre a proibição do trabalho aos domingos: - "Como o povo come todos os dias se deve permitir que trabalhe todos os dias". (MANDEL, 1972, p. 123)

A Alemanha se desenvolve como potência industrial mais tarde em relação a Grã Bretanha ou a França, por várias razões. Não possui unidade política; as comunicações entre as diversas áreas potencialmente industriais são muito precárias, estas áreas - onde há reservas minerais - se acham na periferia do país, demasiado distantes dos centros populacionais; a Alemanha não é rica nem por sua agricultura nem por seu comércio; e, finalmente, os portos alemães do Mar do Norte estão longe das rotas do Atlântico para competir com êxito com o comércio britânico ou holandês, até que o barco a vapor reduza a importância deste fator. Todas estas dificuldades econômicas da Alemanha são superadas entre 1830 e 1880 (HEADER, 1991, p. 73-74).

Portanto, ao tempo da fundação da colônia de Santa Cruz realizava-se na Alemanha a unidade política, se acumula capital para sua inversão na indústria e se transforma o sistema de transporte. Este processo acelerado de industrialização traz no seu bojo a urbanização e a transformação das técnicas de produção no campo, o que ocasiona um excedente populacional que permite e força a imigração. Este fato, coloca as colônias fundadas a partir da segunda metade do século 19 por alemães no Rio Grande do Sul em um contexto diferente daquela da fundação de São Leopoldo em 1824 (CUNHA, 1991, p. 110-174; 1995, p. 28-61; 2015, p. 80-103). 


\section{A família imigrante de Santa Cruz}

A publicidade dos agentes de imigração autorizados por países americanos, entre eles o Brasil, suscita esperanças de sobrevivência aos que sofrem os efeitos do processo de industrialização (WITT, 2015). Desta forma, os que emigram para o Brasil, não são somente os camponeses desapropriados, apesar de representarem a maioria, mas também artesãos incapazes de competir com as forças econômicas em ascensão. A documentação analisada permite concluir que $61 \%$ dos colonos instalados em Santa Cruz entre 1849 e 1854 são camponeses e, portanto, 39 \% são artesão, em sua maioria carpinteiros, sapateiros, pedreiros, negociantes, ferreiros, alfaiates, marceneiros, padeiros, tecelões, entre outros. ${ }^{\text {iii }}$ Todos recebem lotes coloniais de 77 hectares demarcados pelo governo provincial e cobertos de mata virgem que devem derrubar para iniciar o cultivo agrícola.

Deste modo, mais que a importância numérica, a presença de artesãos entre os imigrantes de Santa Cruz teve efeitos que não podem ser desprezados, sobre a evolução social da colônia e a rapidez com que se instala e prospera o núcleo urbano da colônia, fundado em 1855 e que deu origem a cidade de Santa Cruz do Sul.

Para completar a caracterização social dos colonos imigrantes de Santa Cruz, na sua fase inicial, é necessário deter-se na análise da família imigrante, elemento essencial para o entendimento de vários aspectos da vida na colônia.

A preferência da concessão dos lotes coloniais recai sobre os imigrantes casados, de tal forma que em uma publicação sobre os direitos deveres e obrigações dos colonos, distribuída na Alemanha por Peter Kleudgen, agente autorizado para a colonização alemã na província do Rio Grande do Sul, diz no seu artigo $3^{\circ}$ :

Segundo os artigos $7^{\circ}, 8^{\circ}, 9^{\circ}$ e $10^{\circ}$ da lei $n^{\circ} 229$, de 4 de dezembro de 1851 , a cada colono casado bem como aos solteiros que casarem após a chegada a Província, finalmente a cada viúva com família, serão doadas 100 mil braças quadradas na colônia de Santa Cruz, ou em outra a ser criada, desde que apresentem o certificado expedido pelo agente autorizado. As terras já estarão demarcadas às custas do Governo Provincial. (KLEUDGEN, 1852, s. p.).

O Artigo $8^{\circ}$ da Lei 229, do governo da província do Rio Grande do Sul (PORTO, 1934, p. 162-163), de 4 de dezembro de 1851, afirma que, “Art. $8^{\circ}$ - Só se consideram com direito de receberem terras os colonos casados ou viúvos com filhos, e os solteiros, que se casarem depois de chegarem à Província”. Peter Kleudgen, faz a seguinte observação a respeito deste artigo:

Um colono solteiro tem como a experiência mostrou, grandes dificuldades; perde tempo com trabalhos caseiros e sente-se sozinho após a jornada de trabalho, sentindo-se solitário e abandonado. Esta a razão da preferência pelos casados. KLEUDGEN, 1852, s.p.). 
A lei provincial $n^{\circ} 229$ e as observações de Peter Kleudgen, provavelmente baseiam-se na experiência dos colonos solteiros fixados em Santa Cruz entre 1849 e 1851, sob a vigência da lei $n^{\circ} 514$ de 28 de outubro de 1848, do governo imperial, que não trata deste particular. Segundo um relatório do diretor da colônia, em julho de 1851 são 63 os lotes distribuídos, dos quais $26(41,2 \%)$ para imigrantes solteiros. ${ }^{\text {iv }}$

Ao que parece, este aspecto da lei $229\left(\right.$ Artigo $8^{\circ}$ ) não é integralmente cumprido no que se refere aos solteiros, te tal sorte que mesmo após a sua vigência, continuam a ser distribuídos lotes sob estas condições.

Uma ideia sobre as dificuldades enfrentadas pelos colonos solteiros e a importância da família como unidade produtiva, é dada pelos depoimentos constantes em oito requerimentos ao presidente da província, diante da publicação de editais que obrigam à efetiva ocupação para a legitimação e legalização da posse dos lotes coloniais:

Diz Jacob Heinen colono, morador nesta Freguezia de Santa Cruz que tomou conhecimento dos editais publicados pelo Ilmo. Diretor da Colônia que todos os prazos coloniais abandonados dos seus proprietários devem reverter ao domínio Provincial, vem respeitosamente perante $\mathrm{V}^{\mathrm{a}}$. Excia. Reclamar o seu prazo colonial, situado na Linha Sinimbu nesta colônia de Santa Cruz sob n ${ }^{\circ}$ 69. Este prazo foi lhe distribuído no anno de 1863 e o suplicante principiou de cultival-o e habital-o, roga a $\mathrm{V}^{\mathrm{a}}$ Excia. neste tempo era solteiro, e, como tal tinha de lutar com muitas dificuldades mas perseverou durante três anos. Reconhecendo porem que um solteiro não pode subsistir numa colônia, e que sua vizinhança consistindo também de homens solteiros, dos quais o suplicante não podia esperar ajuda alguma, ficou obrigado de deixar, entretanto, o prazo colonial e de procurar outra arrumação. O suplicante agora casado deseja muito continuar de cultivar e habitar o dito prazo colonial, e com ele está cumprindo as ordens que este Directorio lhe impôs de limpar a picada e roçar a vegetação vem pedir respeitosamente a $\mathrm{V}^{\mathrm{a}}$ Excia. de tomar em consideração o que o suplicante tem a honra de alegar, a fim de que $\mathrm{V}^{\mathrm{a}}$ Excia. se digne de mandar o que for de justiça. Jacob Heinen. Santa Cruz, $4^{\circ}$ de junho de $1871 .^{v}$

Os outros sete colonos apresentam os mesmos motivos para o abandono de seus respectivos lotes coloniais e, igualmente, solicitam a consideração do governo.

Depreende-se o significado da família como unidade de produção e consumo e a importância da mulher como mão de obra. Jean Roche afirma que,

É toda a família que trabalha, sobretudo na primeira geração. Apenas se toma o tempo de preparar a refeição do dia seguinte: os homens, as mulheres e muitas vezes as crianças, são absorvidos, de manhã a noite, no desbravamento da floresta. Se a derrubada e a queimada são tarefas masculinas, as mulheres semeiam, plantam, mondam, colhem, ordenham e devem ainda, fazer o pão, a manteiga, a lixívia, etc. (ROCHE, 1969, p. 559).

É a família que detém e organiza o essencial da vida econômica da colônia, é no seu contexto interior que se produzem os bens necessários a sua subsistência; ou outros, como troca de bens ou serviços com outras famílias. Este aspecto a diferencia fundamentalmente da família urbana que tem a produção organizada fora de si, no exterior do grupo e espaço domésticos. 


\section{Estrutura dos domicílios na colônia de Santa Cruz em 1851}

Para Louis Henry, "o domicílio é constituído por um grupo de pessoas vivendo em comum sob a autoridade do chefe da unidade domiciliar, ou um grupo de pessoas que vivem sob um mesmo teto ou habitação" (1977, p. 29). Para a colônia de Santa Cruz, considera-se como domicílio um lote colonial sob a autoridade de seu titular residente, condição para a efetivação da propriedade -, podendo comportar mais de uma família biológica, composta pelos pais e filhos, entendido como tal casais ou viúvos e viúvas com ou sem filhos (HENRY, 1977, p. 29-30).

Analisando o relatório do diretor da colônia de 16 de junho de $1851^{\text {vi }}$ e baseandose na tipologia organizada por Eni de Mesquita Samara (1980, p. 27), tem-se na colônia de Santa Cruz um total de 63 lotes ocupados, portanto considerados domicílios familiares. Dos quais, 29 (46,0 \%) são domicílios nucleares; 26 (41,2\%) são domicílios singulares; quatro $(6,4 \%)$ domicílios aumentados; dois $(3,2 \%)$ domicílios desconexos; e, dois $(3,2 \%)$ domicílios fraternos.

Dos domicílios considerados do tipo nuclear, cinco deles são ocupados somente pelo casal, quatro sem filhos e um deles com um filho solteiro cultivando outro lote colonial e nele residindo, constituindo, portanto, outro domicílio. Nos casais sem filhos a idade média das mulheres é de 26 anos e a dos homens de 33 anos. Das famílias com um único filho, uma delas é formada por uma viúva de 31 anos e sua filha de quatro anos de idade.

Os domicílios singulares, 41, 2 \% do total, são ocupados por colonos solteiros, a revelia do texto da lei $\mathrm{n}^{\circ} 229$. Interessante, contudo, examinar a idade dos indivíduos moradores dos domicílios do tipo singular. 85,6 distribuem-se na faixa etária dos 18 aos 39 anos de idade, o que pode ser considerado o esperado, considerando-se a capacidade produtiva do homem. Estranha é a concessão de lotes a dois imigrantes relativamente idosos - um de 49 anos e outro de 51 anos de idade -, e mais, a dois adolescentes - um de 11 anos e outro de 16 anos de idade.

Quanto aos lotes distribuídos e, supostamente, ocupados por dois adolescentes, considerando a necessidade de efetiva ocupação como garantia de posse, isto pode evidenciar o favoritismo da direção da colônia ou do governo da província na distribuição de lotes coloniais a imigrantes alemães em Santa Cruz. Uma diferenciação de oportunidades já na origem da colônia, que dentro do processo histórico é responsável pela gênese das classes fundamentais do capitalismo: - um proletariado e uma burguesia 
de origem camponesa ao lado de um campesinato que contemporaneamente é recriado pelo capital através dos processos organizativos da agroindústria, especialmente vinculada a produção e industrialização do tabaco.

Ambos os lotes, de números 42 e 43, concedidos respectivamente a Germano Hilbig (11 anos) e a Ambrozio Putzke (16 anos) ficam vizinhos aos lotes de número 40 e 41, pertencentes a Francisco Hilbig e a Christiano Putzke. Supondo-se parentesco ou especificamente filiação dos primeiros em relação aos segundos, fica claro que determinadas famílias apoiadas pela conivência oficial, usavam deste artifício para duplicar sua área agricultável e a produção de excedente comercializável.

Quatro dos domicílios descritos pelo diretor da colônia em seu relatório, podem ser classificados de domicílios aumentados. O primeiro deles é composto pelo titular do lote, sua mãe e uma família de agregados com o mesmo sobrenome - certamente parentes. O segundo domicílio pertence a um colono solteiro mais uma família de agregados, parentes seus. $\mathrm{O}$ terceiro pertence a um casal, mais uma agregada de 22 anos que, devido a doença da mulher do proprietário a substitui nos afazeres domésticos. Finalmente, temse o quarto domicílio que é ocupado por um viúvo com três filhos mais um casal de agregados. No exame da situação de cada um destes domicílios depreende-se que o agregado representa muito mais um sócio no desbravamento e cultivo do lote do que um empregado, geralmente um parente disposto a auxiliar na exploração da área em troca da divisão igualitária dos resultados.

Os dois domicílios classificados como desconexos, assim o foram devido a aparente estrutura da organização do trabalho, diferente dos demais. Em ambos os casos aparece claramente o caráter de sociedade na propriedade, exploração e usufruto do lote colonial. Em um deles o colono de 43 anos, declara-se sócio de outro com sua família. No outro domicílio, dois colonos solteiros se declaram coproprietários do lote.

Os domicílios fraternos são os que não possuem um chefe aparente, nos dois casos tem-se irmãos solteiros e órfãos, explorando seus lotes. Um deles composto por um casal de irmãos. Ele com 28 anos e ela com 30 anos de idade. No outro convivem cinco irmãos, quatro homens e uma mulher. Os homens com respectivamente 18, 16, 13 e seis anos e a mulher com oito anos de idade.

Analisando a estrutura familiar dos domicílios na fase de instalação da colônia de Santa Cruz, é possível afirmar que a grande proporção de domicílios ocupados por homens solteiros, seja uma característica transitória, que em fase posterior culmine na absoluta predominância dos domicílios nucleares como padrão característico das 
populações imigrantes já adaptadas. A composição de família preenche as necessidades impostas pela exploração do lote colonial em uma região carente de mão de obra.

\section{O casamento tardio}

A revolução industrial na Europa, com a ajuda da força mecânica destruiu o monopólio dos trabalhadores masculinos nas tarefas difíceis. A mão de obra masculina relativamente cara, se vê substituída por mão de obra mais barata mediante a absorção do trabalho feminino e infantil.

A incorporação da mulher no trabalho produtivo significa um determinado incremento nos custos de reprodução da força de trabalho familiar, porém não uma duplicação. Pois ao incorporar-se a mulher, ela não necessita pagar novamente a casa, a comida, etc. O salário adicional que necessita a mulher neste contexto é somente uma parte do salário do homem. Os custos da recriação da força de trabalho familiar aumentam ainda menos com a incorporação das crianças ao processo produtivo.

Os trabalhadores adultos, muitas vezes são demitidos, principalmente na indústria têxtil. Sendo assim, o trabalho feminino e infantil não só proporciona um novo meio para a burguesia baixar o valor dos salários, mas se apresenta como necessário para que a classe trabalhadora possa sobreviver. Desta forma, a incorporação das crianças e das mulheres ao processo produtivo é do interesse tanto da classe burguesa, para incrementar seus lucros, como para o proletariado para poder subsistir.

Para isto, é necessário a eliminação de todos os obstáculos à dita incorporação: - o matrimônio precoce e o matrimônio frequente. A prolongação da juventude, pelo retardamento do matrimônio, significa, para os empresários industriais, a prolongação do tempo no qual podem apropriar-se da mais-valia absoluta produzida pelo trabalho juvenil. A incorporação da mulher é tanto mais fácil enquanto ela não casa, e a mais-valia proporcionada pelo trabalho feminino se incrementa mais quando uma proporção das mulheres não se casa ou se casa mais tarde.

Assim, se pode entender também a importância que teve Malthus (1826). Ao propor o matrimônio tardio em seu Primeiro ensaio sobre a população de 1798 (SZMRECSÁNYI, 1982), Malthus proveu a burguesia dos mecanismos para poder absorver a mão de obra juvenil, e com ela, os mecanismos para produzir uma mais-valia absoluta. Claro está que a burguesia não é contrária à reprodução biológica da sua força de trabalho. Porém, este processo procriativo pode ser retardado até idades mais 
avançadas, e também não necessita necessariamente ser levado a cabo por todas as mulheres. A burguesia não é favorável a restrição da procriação neste momento concreto da história, e Malthus cita bem as necessidades dela; retardar o matrimônio, estimular inclusive o celibato, porém nenhuma restrição a reprodução dentro do matrimônio (SZMRECSÁNYI, 1976).

Tomando-se os padrões de nupcial idade estudados pelo demógrafo Vanderbroeke (1976, p. 111-117), em Flandres, na Bélgica, observa-se evolução significativa quanto a idade média das mulheres ao casamento: - entre 1620 a 1639, 24, 3 anos; - entre 1700 a 1709, 25,3 anos; - entre 1750 a 1759, 26,3 anos; - entre 1800 a 1809, 27,9 anos; e, - de 1850 a 1859, 29, 7 anos de idade. Estas cifras baixam até alcançar 26 anos no final do século 19. Vanderbroeke inscreve essa evolução comportamental dentro do processo de proletarização do povo flamengo que ocorreu nesta época (DIERCKXSENS, 1982, p. 62)

Supondo situação semelhante dentro do processo de industrialização que ocorre na Alemanha após sua unificação, tem-se provavelmente também aí um retardamento do casamento. Knodel (1974, p. 70) oferece alguns dados a respeito, informando que entre 1871 e 1910, a idade média ao casamento do homem oscila entre 29 e 28 anos, e a idade da mulher ao casamento entre 26 e 25 anos de idade.

Nadalin (1978, p. 256) situa a idade média ao primeiro casamento em 26,5 anos para a mulher e 29,5 anos de idade para o homem na Prússia, no período de 1876 a 1900. Um dado importante considerando-se que dos 63 lotes descritos pelo diretor da colônia de Santa Cruz em seu relatório de 16 de julho de 1851, 54 são ocupados por colonos imigrantes da Prússia e da Silésia, 85,7\% do total (CUNHA, 1995, p. 116-135).

$\mathrm{Na}$ ausência de qualquer outra informação sobre os colonos de Santa Cruz, senão o relatório de Buff de 1851, chega-se, pelos dados nele contidos, a uma idade média de 27 anos para mulher e de 32 anos para o homem. Cifras prováveis, com alguma margem de erro, para a idade dos cônjuges ao casamento. Dados comparáveis para os encontrados na Europa no mesmo período e especificamente na Alemanha, considerando-se uma regularidade na evolução da idade média ao casamento diante dos dados disponíveis.

A prática do casamento tardio, cede diante de uma nova realidade, essencialmente camponesa em sua primeira fase, numa clara resposta as exigências da vida material dos imigrantes e seus descendentes no país receptor. Um exemplo dessa mudança de comportamento pode ser buscado nos dados fornecidos por Nadalin (1978, p. 256), para a colônia alemã de Ijuí (NEUMANN, 2016), no Rio Grande do Sul. Para o 
período de 1910 a 1930 a idade média do homem ao casamento é de 23,5 anos e da mulher de 20,4 anos. Ora, considerando-se a fundação da colônia em 1890 e o término do fluxo de imigrantes para ela em 1912 (ROCHE, 1969, p. 127), os dados fornecidos por Nadalin, atestam a mudança da prática corrente na Europa no século 19, o que em pesquisa futuras talvez possa ser comprovado no que diz respeito a nupcialidade dos imigrantes e seus descendentes em Santa Cruz.

\section{Considerações finais}

A partir da documentação usada para este trabalho pode-se concluir, que:

- A presença de grande número de artesãos entre os imigrantes chegados a colônia de Santa Cruz na fase de sua instalação tem sua explicação na revolução industrial que ocorre na Alemanha a partir da segunda metade do século 19.

- A família é fundamental no processo de colonização, fator reconhecido oficialmente. Contudo, a concessão de lotes coloniais a imigrantes solteiros, apesar de contrariar o próprio tex to da lei que regulamenta a imigração e colonização no Rio Grande do Sul neste período, é prática constante.

- Os domicílios do tipo singular, refletem um caráter de transitoriedade, permitindo supor que os domicílios estruturados a partir da família nuclear sejam em fase posterior a regra geral, como própria condição de sobrevivência do colono imigrante. A presença de agregados ou famílias de agregados não possui para o imigrante o mesmo significado que possui nos estabelecimentos agrícolas da fase pré imigratória, correspondendo a uma categoria equivalente a de um sócio.

- A realidade material das colônias de imigrantes, determina a transformação dos padrões de nupcialidade vigentes no país de emigração, o que comprova que a composição da família preenche as necessidades impostas para a exploração do lote colonial em uma região carente de mão de obra. E influencia, igualmente, o comportamento demográfico desta população caracterizado pelo fluxo produtivo e ritmo de crescimento econômico com características claramente capitalistas ainda que vinculadas a produção familiar em lotes agrícolas coloniais. 


\section{Referências}

ARQUIVO HISTÓRICO DO RIO GRANDE DO SUL. Relatório do Diretor da Colônia de Santa Cruz João Martinho Buff, de 16 de julho de 1851.

ARQUIVO HISTÓRICO DO RIO GRANDE DO SUL. Diretoria da colônia de Santa Cruz. Relatório do diretor Affonso Mabilde, de 2 de novembro de 1866.

ARQUIVO HISTÓRICO DO RIO GRANDE DO SUL. Colonização e imigração - Caixa 286.

BARROS, Eliane Marli e LANDO, Aldair Cruxên. Capitalismo e colonização: os alemães no Rio Grande do Sul. In: DECANAL, José Hildebrando (org.). RS: imigração e colonização. Porto Alegre, Mercado Aberto, 1980. p. 9-46.

COSTA, Iraci del Nero da. Populações mineiras: sobre a estrutura populacional de alguns núcleos mineiros no alvorecer do século XIX. São Paulo, IPE-USP, 1981.

CUNHA, Jorge Luiz da. Os colonos alemães e a fumicultura. Santa Cruz do Sul, Rio Grande do Sul 1849-1881. Santa Cruz do Sul, FISC, 1991.

CUNHA, Jorge Luiz da. Rio Grande do Sul und die deutsche Kolonisation. Ein Beitrag zur Geschichte der deutsch-brasilianischen Auswanderung und der deutschen Siedlung in Südbrasilien zwischen 1824 und 1914. Santa Cruz do Sul, Léo Quatke, 1995.

CUNHA, Jorge Luiz da. Da miséria fugiram! (pelo menos a maioria). In: FISCHER, Luís Augusto e GERTZ, René Ernaini. Nós, os teuto-gaúchos. Porto Alegre, UFRGS, 1996. p. 255-266.

CUNHA, Jorge Luiz da. Os efeitos práticos das políticas provinciais e imperiais sobre a colonização de territórios do Rio Grande do Sul com imigrantes europeus no século XIX. In: RADÜNZ, Roberto e HERÉDIA, Vania Beatriz Merlotti (Orgs.). Imigração e sociedade. Fontes e acervos da imigração italiana no Brasil. Caxias do Sul, Educs, 2015. p. 80-103.

DIERCKXSENS, Wim. Una interpretación histórica de la populación. In: REVISTA DE CIENCIAS SOCIAIS. São José, U.C.R. Out. 1976.

DIERCKXSENS, Wim. Capitalismo y población; la reproducción de la fuerza de trabajo bajo el capital. São José, Educa, 1982.

FREYRE, Gilberto de Mello. Casa grande \& senzala. Formação da família brasileira sob o regime da economia patriarcal. São Paulo, Global, 2003.

HEADER, H. Europa en el siglo XIX desde 1830 hasta 1880. Madrid, Aguilar, 1973.

HENRY, Louis. Técnicas de análise em demografia histórica. Curitiba, UFPR, 1977

KLEUDGEN, Peter. Die deutsche Kolonie Santa Cruz, Provinz Rio Grande do Sul, SüdBrasilien, von Peter Kleudgen, bevollmächtigtem Agenten gennanter Provinz. Hamburg, J. J. Nobilig, 1852.

KNODEL, John E. The decline of fertility in Germany, 1871-1939. Princeton, Princeton University Press, 1974.Pp. 70

MALTHUS, Thomas Robert. An essay on the principle of population; or, a view of its past and presente effects on human happiness. London, John Murray/Albermarle Street, 1826. 
MANDEL, Ernest. Tratado de economia marxista. México, Era, 1972.

MARCÍLIO, Maria Luiza. Crescimento demográfico e evolução agrária paulista. 17001836. São Paulo, HUCITEC/EDUSP, 2000.

NADALIN, Sérgio Odilon. Une Paroisse d'origine germanique au Brasil: la communaute evangelique lutherienne a Curitiba entre 1866 et 1969. Paris, 1978, Doctorat 3e. cicle, École de Hautes Etudes em Sciences Sociales.

NEUMANN, Rosane Marcia. Uma Alemanha em miniatura. O projeto de imigração e colonização étnico particular da Colonizadora de Meyer no Noroeste do Rio Grande do Sul (1897-1932). São Leopoldo, Oikos/UNISINOS, 2016.

NIPPERDEY, Thomas. Deutsche Geschichte. München, Beck, 1991.

PORTO, Aurélio. O trabalho alemão no Rio Grande do Sul. Porto Alegre, Santa Terezinha, 1934.

RIO GRANDE DO SUL. Relatório ao Ilmo. E Exmo. Sr. Conde de Caxias Presidente da Província, respectivo a prosperidade, agricultura e população da colônia de Santa Cruz. Do diretor da colônia João Martinho Buff em 16 de julho de 1851.

ROCHE, Jean. A colonização alemã no Rio Grande do Sul. Porto Alegre, Globo, 1969.

SAMARA, Eni de Mesquita. A família brasileira. São Paulo, Brasiliense, 1986.

SAMARA, Eni de Mesquita. A família na sociedade paulista do século XIX (1800-1860). São Paulo, 1980. Tese de doutoramento - USP.

SAMARA, Eni de Mesquita. A história da família no Brasil. Revista Brasileira de História. São Paulo, v.9, n.17. p.7-36, set/fev 1988/89. Número Especial.

SZMRECSÁNYI, Tamás (org. e trad.). MALTHUS, Thomas Robert, 1766-1834. Economia. São Paulo, Ática, 1982.

VANDERBROEKE C. Het Huwlyks em Voortplantingspatroon in Vlaanderen em Brabant (17 de - 19 de eeuw). (Padrões de nupcialidade e de reprodução em Flandres e Brabante, séculos XVIII-XIX). In: TYDSCHRIFT VOOR SOCIALE GESCHENDENIS, Maio 1976. p. 111-117.

VIANA, José Francisco de Oliveira. Populações meridionais do Brasil. Brasília, Senado Federal/Conselho Editorial, 2005.

WITT, Marcos Antônio. Em busca de um lugar ao sol. Estratégias políticas. Imigração alemã, Rio Grande do Sul, século XIX. São Leopoldo, Oikos/Editora Unisinos, 2015.

Recebido: 11/03/2019

Aceito: $31 / 03 / 2019$

Publicado: 13/05/2019

\footnotetext{
' Doutor em História. Professor Titular da Universidade Federal de Santa Maria - UFSM. E-mail: jlcunha11@yahoo.com.br

ii “Tal fato se comprova pela observação de que neste período - 1830 a 1844 - São Leopoldo não recebeu nenhum imigrante”. São Leopoldo foi a primeira colônia alemã, fundada no Rio Grande do Sul em 1824. (BARROS, LANDO, 1980, p. 28).

iii ARQUIVO HISTÓRICO DO RIO GRANDE DO SUL. Diretoria da colônia de Santa Cruz. Relatório do diretor Affonso Mabilde de 2 de novembro de 1866.
} 
iv RIO GRANDE DO SUL. Relatório ao Ilmo. E Exmo. Sr. Conde de Caxias Presidente da Província, respectivo a prosperidade, agricultura e população da colônia de Santa Cruz. Do diretor da colônia João Martinho Buff em 16 de julho de 1851.

v ARQUIVO HISTÓRICO DO RIO GRANDE DO SUL. Colonização e imigração - Caixa 286.

vi ARQUIVO HISTÓRICO DO RIO GRANDE DO SUL. Relatório do Diretor da Colônia de Santa Cruz. João Martinho Buff, de 16 de julho de 1851. 